University of Nebraska - Lincoln

DigitalCommons@University of Nebraska - Lincoln

Educational Psychology Papers and

Publications

Educational Psychology, Department of

2019

What's Past Is Prologue: Advancing Feminist Psychological

Research on LGBTQ+ Genders

Elliot A. Tebbe

Follow this and additional works at: https://digitalcommons.unl.edu/edpsychpapers

Part of the Child Psychology Commons, Cognitive Psychology Commons, Developmental Psychology Commons, and the School Psychology Commons

This Article is brought to you for free and open access by the Educational Psychology, Department of at DigitalCommons@University of Nebraska - Lincoln. It has been accepted for inclusion in Educational Psychology Papers and Publications by an authorized administrator of DigitalCommons@University of Nebraska - Lincoln. 


\title{
What's Past Is Prologue: Advancing Feminist Psychological Research on LGBTQ+ Genders
}

\author{
Elliot A. Tebbe \\ Department of Educational Psychology, University of Nebraska-Lincoln, Lincoln, NE, USA \\ Correspondence - Elliot A. Tebbe, Department of Educational Psychology, University of Nebraska-Lin- \\ coln, 114 Teachers College Hall, Lincoln, NE 68588, USA. Email: etebbe2@unl.edu
}

Keywords: feminist science and epistemology, gender development, LGB Issues, queer identity, sexual identity, sexual fluidity, nonbinary sexuality, transgender issues

In my introduction to the special section on LGBTQ genders in this issue of the Psychology of Women Quarterly (PWQ), I highlight and place in context the significant contributions of this special section to theory and the broader psychological literature on gender. For several years now, the Society of Psychology of Women's Section 4 (Section on Lesbian, Bisexual, and Transgender Concerns) of the American Psychological Association (APA) has invited authors of ground-breaking empirical research on gender and sexuality to submit papers to present at the annual APA convention. Through the years, we have seen cutting edge research presented that has pushed the boundaries of

Published in Psychology of Women Quarterly 43:3 (2019), pp 271-274.

DOI: 10.1177/0361684319847121

Copyright (c) 2019 Elliot Tebbe. Published by SAGE Publications. Used by permission. 
existing theory and knowledge on gender and sexuality. And scholars have increased our understanding of how to best serve the needs of individuals and communities diverse in gender and sexual orientation. Of course, expanding far beyond the scope of Section 4's annual APA symposium, there has been a veritable explosion in the broader literature on research related to LGBTQ genders (e.g., Moradi et al., 2016; Singh \& Shelton, 2011). In my role as President of Section 4, and with $P W Q$ Editors Mary Brabeck and Dawn Szymanski, we saw an opportunity in a pivotal time to advance efforts to highlight ground-breaking gender and sexuality research by inviting an article that synthesized the extant literature and could offer a theoretical foundation for understanding gender as a psychosocial phenomenon. We invited Heidi Levitt, a leading researcher in this field, to reflect on her work and draw on hers' and others' empirical findings to articulate a theory of LGBTQ gender development. Levitt's (2019) invited article serves as the core contribution for this special section of $P W Q$. We also invited reflections from two additional leading scholars in the field, Bonnie Moradi and Laurel Watson. We asked them to reflect on the implications of Levitt's article for research (Moradi, 2019) and teaching and clinical practice (Watson, 2019). In her invited response, Bonnie Moradi elucidates a framework of power by which to explicate the implications of Levitt's psychosocial theory of LGBTQ+ genders on future scholarship in this area. In the second invited response, Watson highlights three main themes that cut across Levitt's psychosocial theory of LGBTQ genders to describe their implications for psychology clinicians, educators, and advocates: (re)defining gender, intersectionality, and social justice.

\section{A Historical Framework for Levitt's Psychosocial Genealogy of LGBTQ+ Gender}

Levitt (2019) uses a historical perspective "of individuals and communities as being shaped by the cultural events and understandings unfolding during those times" (p. 33) to provide in-depth analysis of gender as a psychosocial construct. Her approach, spanning multiple academic disciplines, including psychology, history, sociology, and anthropology, provides us with a rich understanding of the complexity and nuances that led to the development and evolution of LGBTQ 
genders across time and contexts. The historical framework that Levitt draws on also links methodological traditions employed by mainstream psychological researchers in the United States with calls from scholars in the Global South to expand on an individual-differences focus by considering gender development as historically dynamic. As Connell (2011) writes,

Gender does not involve a timeless dialogue of the biological and symbolic-it involves vast formative processes in history, both creative and violent, in which bodies and cultures are equally at stake and are constantly being transformed, sometimes to destruction. (p. 108)

Connell's statement powerfully captures U.S. history as a nation founded through Western colonization and expansion (Wolfe, 2006). Colonialism in the United States-as in many other places in the world-systematically and violently destroyed Indigenous practices and cultural understandings of gender and sexuality (Goldberg, 1991; Williams, 1986). Through colonization practices, individuals and cultural traditions that recognized and celebrated gender and sexuality as fluid and diverse were punished, erased, and systematically eradicated (Goldberg, 1991; Han \& O’Mahoney, 2014; Williams, 1986). Western colonization brought with it narrow, binary conceptions of gender and sexuality that harshly punished anyone who deviated from these cultural norms. With that historical backdrop, Heidi Levitt traces the history of LGBTQ genders in the United States in order to understand how gender functions within communities, in response to oppressive forces that remain in the postcolonial United States. With this approach, Levitt paves new paths for the development of feminist epistemologies that go beyond the investigation of individual differences and individual processes and functioning. She directs attention to the inherently collective processes that underlie identity formation within communities. This paradigmatic shift is a call to all of us engaged in gender scholarship to consider the broader set of social dynamics from which gender is generated within societies and across our violent histories.

In addition to providing a richer understanding of the complex and nuanced ways in which gender communities and identities develop in the face of societal forces, Levitt identifies avenues for recognizing, 
celebrating, and ultimately, investigating and understanding the resistance and resilience of individuals and communities marginalized on the basis of gender and sexuality. Although recent psychological research has investigated the resilience strategies that LGBTQ people use in response to minority stress (e.g., Bowleg, Huang, Brooks, Black, \& Burkholder, 2008; Breslow et al., 2015; Bruce, Harper, \& Bauermeister, 2015; Budge et al., 2013; Singh \& McKleroy, 2011), these efforts have tended to focus on individual processes. What Levitt offers us, through her lens of critical feminist history, is perspective on how individual forms of resilience and resistance transform communities over time to create positive spaces where acceptance, security, belonging, and shared values manifest in the lives of individual community members. In line with LGBTQ health scholars across other disciplines (e.g., Landers, Pickett, Rennie, \& Wakefield, 2011), this lens opens new avenues for considering prevention and intervention strategies that can leverage existing community strengths and dynamics in order to further promote well-being and attenuate existing health disparities.

\section{Gender as Framed Across Domains and Major Effects}

Levitt advances theory on gender and sexuality by identifying a larger framework by which we may understand why genders have developed within communities and the effects such genders have on individuals. She provides compelling evidence from her own work and, where it exists, consistent and complementary findings from the larger body of empirical research, to identify four domains within which genders function to address individual and community needs: psychological, cultural, interpersonal, and sexual. Across these domains, genders develop and are expressed in response to core needs from individuals within communities related to identity and authenticity, power and security, belongingness and connection, and valuation of gender and gender diversity. With this framework, Levitt advances theory by articulating how- when core needs are met-enacting authentic gender exerts positive effects and even at times counters the negative impacts of marginalization and oppression for individuals and communities. By synthesizing findings from primarily qualitative research where the cultural context of data is explicitly and deeply embedded, Levitt offers us an opportunity to understand how gender-for 
all genders-acts to function in such a way that is not only summative but also richly descriptive of the lived experiences of communities and individuals in both the past and present.

Levitt (2019) also describes the overlap and interconnectedness of gender and sexuality. In early research, gender and sex-and gender and sexuality-were often conflated empirically and conceptually (Muehlenhard \& Peterson, 2011; van Anders, 2015). This led researchers and scholars to call for recognition of the conceptual differences between the two and to empirically study gender and sexuality (and, by extension, gender identity, and sexual orientation) as separate and distinct constructs (APA, 2012). However, throughout Levitt's article, we see an interplay between the two unfolded, that is shaped in its manifest expression and embodiment by the context in which individuals navigate a hostile world. Levitt bolsters the burgeoning advancement in our understanding of how gender evolves alongside sexuality and in response to the larger context in which individuals and communities live.

\section{Advancement and Embodiment of Feminist Epistemologies in Psychological Research}

Throughout her article, Levitt (2019) assumes an explicit positionality, in line with feminist research practices (e.g., Fischer \& DeBord, 2013; Muhammad et al., 2015). Levitt opens her article by describing her early career experiences in conducting LGBTQ research and some of the limitations she faced in those early years, including fears related to employment discrimination and barriers to career advancement, lack of available mentorship, and the dearth of literature on and by LGBTQ+ people. She describes how her entrance into a vibrant lesbian separatist community, and subsequent observations of the gender norms and dynamics that shaped individuals within that community, drove her passion for greater understanding of LGBTQ genders. By positioning herself so explicitly in her work, we are able to see the manner in which the critical feminist approach that she adopts in her work so richly enhanced the quality of her findings. More specifically, Levitt describes the need to be a part of and connected to the communities she studied, noting the ways in which these connections build and maintain trust between researchers and community members, and 
also greatly augment understanding and analysis of study findings in cultural context. Throughout Levitt's work, we see the ways in which this careful attention and commitment to researcher-community embeddedness and partnership provides the rich and contextualized data from which Levitt's theory of gender and gender identity cultures is derived. Levitt's theory and the manner in which she presents it here further underscores existing calls (e.g., Namaste, 2009; Singh, Richmond, \& Burnes, 2013; Tebbe \& Budge, 2016) for researchers to engage in community partnerships and to be a part of and align closely with individuals in communities in which research is being conducted. As Levitt so thoughtfully and compellingly illustrates, as a psychosocial construct, gender can only be understood in the larger contexts in which it functions and develops over time.

Levitt notes early in her article that at the time she began her work in this area, she was not able to locate any research on LGBTQ genders in psychology, turning instead to sociology and women's studies for scholarship. Although psychological research and scholarship on LGBTQ genders has grown substantially since that time (e.g., Moradi et al., 2016; Singh \& Shelton, 2011), as a field, psychology continues to lag behind its sibling disciplines both in breadth and depth in capturing the nuanced and interactional development and expression of gender across individuals and within communities. Levitt's unifying theory of gender and gender identity cultures gives feminists, and all psychologists, a path forward for considering how we might advance psychological science through the application of rigorous empirical methods grounded in a new type of interdisciplinary paradigm that holds in equal value (a) explicitly recognizing context and history, (b) understanding and elucidating community structures and functions, and (c) investigating and situating individual experience and functioning.

Declaration of Conflicting Interests The author declared no potential conflicts of interest with respect to the research, authorship, and publication of this article.

Funding The author received no financial support for the research, authorship, or publication of this article. 


\section{References}

American Psychological Association. (2012). Guidelines for psychological practice with lesbian, gay, and bisexual clients. American Psychologist, 67, 10-42. doi:10.1037/aoo24659

Bowleg, L., Huang, J., Brooks, K., Black, A., \& Burkholder, G. (2008). Triple jeopardy and beyond: Multiple minority stress and resilience among black lesbians. Journal of Lesbian Studies, 7, 87-108. doi:10.1300/j155v07no4_06

Breslow, A. S., Brewster, M. E., Velez, B. L., Wong, S., Geiger, E., \& Soderstrom, B. (2015). Resilience and collective action: Exploring buffers against minority stress for transgender individuals. Psychology of Sexual Orientation and Gender Diversity, 2, 253-265. doi:10.1037/sgdoooo117

Bruce, D., Harper, G. W., \& Bauermeister, J. A. (2015). Minority stress, positive identity development, and depressive symptoms: Implications for resilience among sexual minority male youth. Psychology of Sexual Orientation and Gender Diversity, 2, 287-296. doi:10.1037/sgdoooo128

Budge, S. L., Katz-Wise, S. L., Tebbe, E. N., Howard, K. A. S., Schneider, C. L., \& Rodriguez, A. (2013). Transgender emotional and coping processes: Facilitative and avoidant coping throughout gender transitioning. The Counseling Psychologist, 41, 601-647. doi:10.1177/0011000011432753

Connell, R. (2011). Gender and social justice: Southern perspectives. South African Review of Sociology, 42, 103-115. doi:10. 1080/21528586.2011.621242

Fischer, A. R., \& DeBord, K. (2013). Critical questioning of social and feminist identity development literature: Themes, principles, and tools. In E. N. Williams \& C. Z. Enns (Eds.), The Oxford handbook of feminist multicultural counseling psychology (pp. 87-111). New York, NY: Oxford.

Goldberg, J. (1991). Sodomy in the New World: Anthropologies old and new. Social Text, 29, 46-56. doi:10.2307/466298

Han, E., \& O'Mahoney, J. (2014). British colonialism and the criminalization of homosexuality. Cambridge Review of International Affairs, 27, 268-288. doi:10. 1080/09557571.2013.867298

Landers, S., Pickett, J., Rennie, L., \& Wakefield, S. (2011). Community perspectives on developing a sexual health agenda for gay and bisexual men. AIDS and Behavior, 15, 101-106. doi:10. 1007/s10461-011-9896-z

Levitt, H. M. (2019). A psychosocial genealogy of LGBTQ+ gender: An empirically based theory of gender and gender identity cultures. Psychology of Women Quarterly, 43, 275-297. doi:10. 1177/0361684319834641

Moradi, B. (2019). Naming gender as axis of power and coalition politics. Psychology of Women Quarterly, 43, 303-308. doi:10. 1177/0361684319850439

Moradi, B., Tebbe, E. A., Brewster, B. E., Budge, S. L., Lenzen, A., Ege, E., ... Flores, M. (2016). A content analysis of literature on trans people and issues: 20022012. The Counseling Psychologist, 44, 960-995. doi:10.1177/0011000015609044

Muehlenhard, C. L., \& Peterson, Z. D. (2011). Distinguishing between sex and gender: History, current conceptualizations, and implications. Sex Roles: A Journal of Research, 64, 791-803. doi:10.1007/s11199-011-9932-5 
Muhammad, M., Wallerstein, N., Sussman, A. L., Avila, M., Belone, L., \& Duran, B. (2015). Reflections on researcher identity and power: The impact of positionality on community based participatory research (CBPR) processes and outcomes. Critical Sociology, 41, 1045-1063.

Namaste, V. (2009). Undoing theory: The "transgender question" and the epistemic violence of Anglo-American feminist theory. Hypatia, 24, 11-32.

Singh, A. A., \& McKleroy, V. S. (2011). "Just getting out of bed is a revolutionary act": The resilience of transgender people of color who have survived traumatic life events. Traumatology, 17, 34-44. doi:10.1177/ 1534765610369261

Singh, A. A., Richmond, K., \& Burnes, T. R. (2013). Feminist participatory action research with transgender communities: Fostering the practice of ethical and empowering research designs. International Journal of Transgenderism, 14, 93104. doi:10.1080/15532739

Tebbe, E. A., \& Budge, S. L. (2016). Research with trans communities: Applying a process-oriented approach to methodological considerations and research recommendations. The Counseling Psychologist, 44, 996-1024. doi:10.1177/0011000015609045

van Anders, S.M. (2015) Beyond sexual orientation: Integrating gender/ sex and diverse sexualities via sexual configurations theory. Archives of Sexual Behavior, 44, 1177-1213. doi:10.1007/s10508-015-0490-8

Watson, L. B. (2019). Gender identity and expression in LGBTQ+ communities: Implications for the practice of psychology. Psychology of Women Quarterly, 43, 298-302. doi:10.1177/ 0361684319846498

Williams, W. (1986). The spirit and the flesh: Sexual diversity in American Indian culture. Boston, MA: Beacon.

Wolfe, P. (2006). Settler colonialism and the elimination of the native. Journal of Genocide Research, 8, 387-409. doi:10. 1080/14623520601056240 